\title{
Public Environmental Awareness and Behaviour in Malaysia
}

\author{
Neo Sau Mei ${ }^{1}$, Choong Weng Wai ${ }^{1}$, Rahmalan Ahamad ${ }^{2}$ \\ ${ }^{1}$ Faculty of Geoinformation and Real Estate, ${ }^{2}$ Faculty of Science, \\ Universiti Teknologi Malaysia, 81310 Johor Bahru, Johor, Malaysia \\ neo0411_saumei@hotmail.com
}

\begin{abstract}
Considering the causes of environmental degradation are mainly due to anthropogenic activities, this study aims to explore the need of indicating the social-psychological factors among Malaysians in qualifying the level of public environmental awareness and behaviour. A nationwide study has been conducted to examine environmental awareness and behaviour from 13 States and three Federal Territories. The result demonstrated current level of environmental awareness and behaviour among Malaysians, as according to the four categories; water pollution, air pollution, waste management and climate change.

Keywords: Environmental Performance Index; Environmental Awareness; Environmental Behaviour; Malaysian

eISSN: 2398-4279 @ 2017. The Authors. Published for AMER ABRA by e-International Publishing House, Ltd., UK. This is an open access article under the CC BY-NC-ND license (http://creativecommons.org/licenses/by-ncnd/4.0/). Peer-review under responsibility of AMER (Association of Malaysian Environment-Behaviour Researchers), ABRA (Association of Behavioural Researchers on Asians) and cE-Bs (Centre for EnvironmentBehaviour Studies), Faculty of Architecture, Planning \& Surveying, UniversitiTeknologi MARA, Malaysia.

https://doi.org/10.21834/ajqol.v2i5.10
\end{abstract}




\subsection{Introduction}

Rapid urbanization and determination to pursuit luxury modern lifestyle among the public has caused environmental degradation. Harmful waste generation, climate change, environmental pollution and ecosystem breakdown, to name a few, are the environmental catastrophes that reduce the quality of life. These have been long articulated by a significant number of researchers from various scientific disciplines (Dominick et al., 2012; Asmuni, Khalili \& Zain, 2012). The root causes leading to these occurrences is triggered by satisfying human greed through aggressive economic activities without due consideration of environmental consequences.

Considering anthropogenic activities are the main causes of environmental degradation, human social psychological factors pertaining to the environment has both direct and indirect implications to quality of life. Despite numerous environmental events and campaigns about anthropogenic pollutions implemented by government and nongovernment institutions that aimed at changing public environmental behaviour, environmental awareness and commitments are less researched and reported. Public awareness and concern towards environmental issues varies at different levels to influence their corresponding environmental behaviour. It should be highlighted that indicating public environmental awareness and behaviour can serve as a useful reference for policy decisions towards a better environment, hence the quality of life.

This article discusses the public environmental awareness and behaviour performance in terms of four (4) categories of water pollution, air pollution, waste management, and climate change and examines the performance level of environmental awareness and behaviour among Malaysians as the outcome of a nationwide survey.

\subsection{Literature Review}

Knowing the significance of exploring environmental awareness of Malaysians, it is essential to understand the context of environmental awareness. According to Hassan, Noordin and Sulaiman (2010), environmental awareness has three (3) concepts that include emotional, attitude and practice of sustainability awareness. With the motivating of psychological factors and emotional forces, the intention to conduct the series of environmentally friendly actions is driven. Based on the study accomplished by Altin et al. (2014), environmental awareness is referred as awareness to the environmental issues and active involvement in environmental organizations. In spite of that, environmental awareness is a trigger to nurture positive attitudes and affection towards positive environmental behaviour (Karatekin, 2014). Hence, the awareness and concern of environmental issues and the causes and adverse impacts are necessary to be measured in an environmental awareness context (Karatekin, 2014). The higher individual cognitive level to environmental issues and the cause-effect schemes, the higher the intentional environmental behaviour. 
Deficiency of environmental awareness to overwhelming environmental problems, urbanizations, industrialization, deforestation, rising global temperature and degradation biodiversity impede the achievements of policy makers' efforts to encounter the environmental stresses (Keles, 2012). As a result, quality of life is reduced and moving out of the track (Keles, 2012). The quality of life can be multi-faceted from the view of economic, ecology, social and human aspects (Marans, 2012; Keles, 2012). Eventually, the concept of quality of life has always linked to environmental issues; henceforth, it captures complete attentions from policy makers in planning and management of our living environment (Marans, 2012). Policymakers are concerned about the reduced quality of life and, therefore, gauging the environmental awareness among Malaysians is considerably significant to the efficiency of policy planning. The designing of policy can cause the environmental protection programme to be far from expected outcomes without the intervention of public environmental awareness consideration.

Environmental behaviour is a prerequisite at countering the environmental disasters (Klöckner, 2013), in particular addressing the key determinant in which moulding human behaviour towards environmentalism. Ostman and Parker (1987) explained environmental behaviour as 'overt and observable actions taken by a person in response to comprehension of environmental issues to which he or she has had an emotional reaction.' Environmental behaviour is not solely established but predicted by environmental awareness and values that considered might influence the specific behaviour or commitment.

Apparently, the fact that poor environmental behaviour can degrade environmental quality has increasingly gained attention among researchers and policy makers (Klöckner, 2013). Therefore, environmental behaviour and the affecting predictors that influence environmental behaviour should be evaluated considering behavioural patterns can significantly affect the environmental quality and the effectiveness of environmental strategies (Singhirunnusorn et al., 2012). Understanding or predicting the environmental behaviour helps in mitigating the environmental perils in social and political contexts considers that environmental issues have been globally existing (Harth, Leach \& Kessler, 2013). In other words, for policy makers, detecting the changes in attitude and behaviour among the general public enables them to recognise what they are doing to improve public environmental behaviour (Owens \& Driffill, 2008). This attempt is important to be notified when it comes to policy making of environmental laws and guidelines. Change in attitude can induce the change in behaviour to be more likely rather than the other way around. Therefore, for an environmental policy to be operative and efficient the government should understand how and what is the motive for the public to perform environmental behaviour. 


\subsection{Methodology}

For the purpose of reflecting the performance of environmental awareness and behaviour to the current localized environmental issues in Malaysia, literature regarding the causes, consequences and remedy on the four (4) categories, namely water pollution, air pollution, waste management and climate change were reviewed. Subsequently, the research instrument which is the self-administered 5-point Likert Scale questionnaire was developed according to the reviewed literature. For environmental awareness questions, the scaling ranged from strongly disagree, disagree, neither agree nor disagree, agree and strongly agree. Meanwhile, the scaling categories for environmental behaviour questions were never, rarely, sometimes, often and very often. However, 'not applicable' was provided for those who might not consider conducting that particular behaviour.

A focus group and pilot study were executed for verification and validation purposes. The questionnaire was designed in three languages, namely Malay, English and Mandarin versions. Later, face-to-face distribution of the paper questionnaire was executed from August to November of the year 2014.

\subsection{Nationwide Survey}

A nationwide survey was conducted for the purpose of determining the level of environmental awareness and behaviour among Malaysians. All 13 States, including Perlis, Perak, Kedah, Pulau Pinang, Pahang, Kelantan, Terengganu, Selangor, Negeri Sembilan, Melaka, Johor, Sabah, Sarawak, and three Federal Territories, including Putrajaya, Kuala Lumpur and Labuan, were covered.

The nationwide survey covers a large portion of regions in Malaysia. Hence, the sampling method used in this study is multistage and stratified sampling. Initially, multistage sampling was adopted for narrowing down the large pieces of Malaysia regions into smaller portions, stages by stages systematically until the sampling units have been reached. Gradually, from the smaller portions of regions, only several selected ultimate sampling units (administrative districts) were examined and tested in this study. After that, the stratified sampling was integrated where the respondents at the selected regions were approached randomly but according to each of the stratified categories. The stratified categories of respondents in this study were based on demographic factors (i.e., gender, living areas such as urban and rural areas and age group). In other words, there was a required number of respondents in each of the stratified categories in terms of demographic factors according to the Malaysian census data in order to ascertain the equal and balanced coverage of the Malaysian public.

The sample size of each state and Federal Territories was calculated by using Slovin's formula, which discloses that 400 respondents per State or Federal Territory were needed for this study. The sample size is calculated accordingly to the Malaysian census data provided by the Department of Statistics, Malaysia. Consequently, the 400 respondents 
were assessed randomly yet accordingly to fit the required respondents' number of each stratified categories of demographic factors.

\subsection{Results and Discussions}

The questionnaires were divided into Section A and Section B to cover Environmental Awareness and Environmental Behaviour respectively. Meanwhile, demography questions on gender, age and living areas (urban and rural areas) were in the last section of the questionnaire. For the environmental awareness section, the segmentation of questions sum up for 21 questions in which four (4) questions were on water pollution, six (6) questions were on air pollution, four (4) questions were on waste management and seven (7) questions were on climate change. Meanwhile, environmental behaviour related questions consisted of the total of 25 questions in which: four (4) questions were on water pollution; five (5) questions were on air pollution; nine (9) questions were on waste management and seven (7) questions were on climate change. There was a total of 6,400 questionnaires gathered.

\subsection{Environmental Awareness on Water Pollution, Air Pollution, Waste Management and Climate Change}

Figure 1 shows the environmental awareness level among Malaysians. Based on the results, the mean score for environmental awareness towards water pollution is 4.43 , which is the highest score among the other measured criteria. Malaysian awareness towards air pollution and solid management show almost a similar score, which is 4.35 and 4.34 , respectively. The least score is climate change (4.22). Most Malaysians are well aware of the factors and consequences of water pollution that occur in various water bodies ranging from lakes, river, drains, oceans and groundwater. Due to fast economic growth and increase of population density, the aquatic environment condition has deteriorated year by year (Othman \& Mohamed, 2012). The situation has been made gradually evident by such things as clean water shortage and eventually residents have sensed the worseness easily. On that account, people are more affected by what they frequently notice and observe (Karatekin, 2014). On the other hand, climate change gains less attention among Malaysians, for most of them do not realize the causes and negative effects of extreme weather. One of the possible explanations is that Malaysia embraces tropical rainforest climate throughout the years. Hence, the effects of climate change such as flood and scorching weather are indirect and difficult for respondents relate to their life as Malaysians experience consistent hot and humid weather in most of the days. Accordingly, the existence of climate change is less likely disputable as the rest of the environmental issues. 
Air quality issues and waste management have more intermediate attention by Malaysians compared to water quality conservation and climate change. From this study, Malaysians are equally aware and concern about air pollution and waste such as solid, liquid and hazardous waste, especially from industry. Air pollution happening in Malaysia is primarily caused by the emissions from motor vehicles, aircraft, industries and area of high population density (Moreno et al., 2009; Dominick et al., 2012). Out of all, traffic is the most contributing source of urban air pollution in developing countries including Malaysia (Afroz, Hassan \& Ibrahim, 2003; Azmi et al., 2010). Therefore, with the increasing number of car users on the road due to the growing national car manufacturing and imported car tax reduction, Malaysian awareness towards air quality deterioration and haze hindrance is affirmed. This scenario has contributed to serious health and respiratory sickness to the public as well. For the waste disposal system in Malaysia, the illegal garbage dumping and waste disposal out of convenience rather than obligation are manifest. These have created absolute attention and worry among Malaysians for its imperfection towards environment and quality of life.

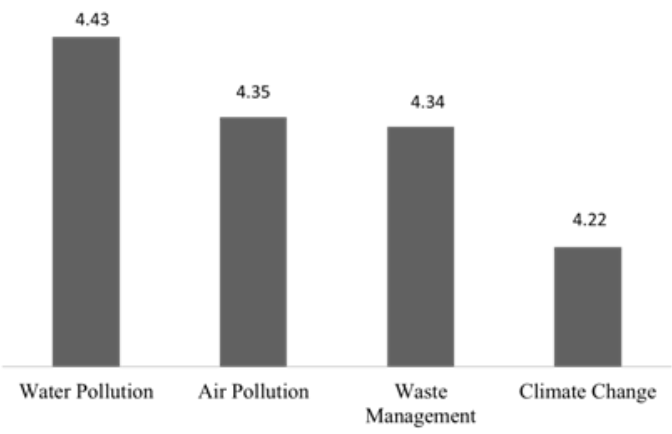

Figure 1: Environmental Awareness Level of Malaysians

\subsection{Environmental Behaviour on Water Pollution, Air Pollution, Waste Management and Climate Change}

The level of environmental behaviour for Malaysians is shown in Figure 2. Most Malaysian environmentally friendly actions towards nature preservation on water quality conservation and climate change show approximately similar score, which are 3.66 and 3.65 , followed by the waste management with environmental behaviour score at 3.51 . As for air quality preservation, the score is 3.43 , which is the lowest performance among Malaysians. From the result in the analysis, water quality preservation and climate change prevention are the most popular environmental friendly actions among Malaysians. For instance, Malaysians ardent in this have strongly related to how far they want to cut cost on water and electricity usage. To further elaborate, saving water quality from declining trend can be through maintaining the clean water sources. Hence, Malaysian aspiration to cut water usage so as 
to reduce the water bill inevitably decreases the used water that is to be treated, thereby helping to conserve the water quality. For climate change relevant pro-environmental behaviour, it is concerned about the extreme weather and global warming that are due to the overwhelmed emissions of greenhouse gases. Over and above, the prior key to inhibiting climate change is by reducing excessive and unnecessary electric usage. Due to all the rationales disputed above, Malaysians are prone to adopt environmental friendly or green products such as energy saving appliances (i.e., washing machines and airconditioners), together with daily water and electric saving habits such as reusing water, switching off electricity when not in use etc. Directly, this occurrence has drifted Malaysians to be efficient in water and climate change conservation.

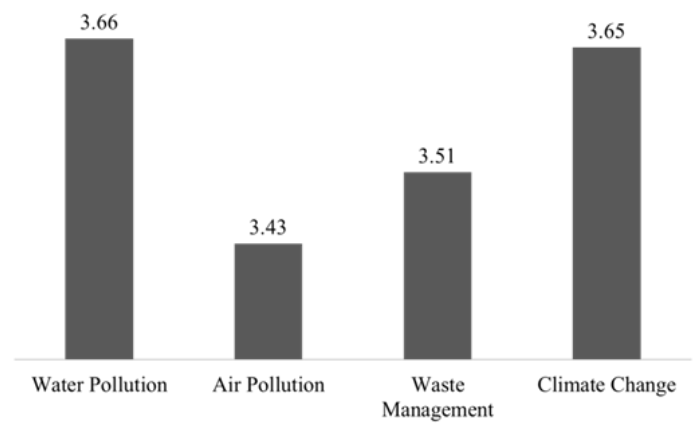

Figure 2: Environmental Behaviour Level of Malaysians

Malaysians react with less concern to maintain the balance of air quality than waste management. Spilling over of waste, especially solid waste, impairs the visual aesthetic quality of the neighbourhood (Chung et al., 2012). As a result, poor waste management becomes more appealing and noticeable to Malaysians. Visual pollution makes an easy impact on human (Karatekin, 2014). It is also worth mentioning that waste management always has been connected with recycling behaviour (Latif \& Omar, 2012; Latif et al., 2013). This concept has been promoted by government departments and public campaigns. For that reason, Malaysians are considerably familiar with the $3 R$ concept. Furthermore, the ongoing 'No Plastic Bag' campaign every Saturday in hypermarkets seems to encourage them to replace plastic bags with reusable shopping bags. Gradually, these titbits of endeavours lead to Malaysian motivation to efficient waste management behaviour. On the other hand, to enhance air quality Malaysians have to deduct the main source of air pollution, which is emission from motor vehicles. The remedy to it most probably would be carpool or car sharing with private car users, in which it lessens the fuel consumptions, thus reducing the car emissions (Seyedabrishami et al., 2012). Due to the individual convenience, the hectic lifestyle does not blend in accordance with most Malaysians to practise car-pooling or public transport when traveling to workplaces, schools and other destinations. On that account, Malaysians hardly could perform well in this category. However, air pollution degrades the 
quality of life and hinders economic growth as it weakens the health condition of Malaysians eventually (Borhan, Ahmed \& Hitam, 2013). Therefore, this result is prompt an alert to the authorities.

\subsection{Conclusion}

As part of Vision 2020 of Malaysia, the government has launched and promoted a series of environmental awareness programmes through different relevant ministries and agencies throughout the year. The examples of national environmental awareness programmes are 'Towards Smart Energy Culture' by Energy Commission Malaysia, 'One State One River Programme' by Ministry of Agriculture, 'Recycle for Nature' by Malaysian Nature Society and so on. Nevertheless, as explained in 'Information Deficit Model', most politicians design environmental campaigns and education that convey environmentally friendly messages to the general public. However, it is not only awareness of environmental issues and policies that lead to environmental action (McKenzie-Mohr, 2000). Nevertheless, the result from this study is crucial to pinpoint the current level of environmental awareness and behaviour among Malaysians, as according to the four (4) environmental issues which are water pollution, air pollution, waste management and climate change. The result also serves as an information base and reference for both the non-profit and government organizations in decision-making, especially in environmental strategies implementation and management. As a nationwide study, the accuracy of the information is considered high as a large scale of Malaysians is covered (Latif \& Omar, 2012).

Environmental awareness and behaviour do not seem positively correlated in this study. This result denotes that a strong environmental awareness level does not indicate greater environmental behaviour level. Environmental awareness alone is not strong enough to predict the behaviour performance towards the preservation of the environment (Hungerford \& Volk, 1990; Klöckner, 2013). It is said that not all people who are aware and sensitive about the environmental issues around them are also motivated to practise and behave in an environmentally-friendly way (Krajhanzl, 2010). People are aware and know what to do for the best of the environment but that does not imply that they have the intention to conduct the action. Consequently, there are many other possible intervening factors such as social-psychological reasons that affect the environmental intentional behaviour of Malaysians.

From this study, it can be concluded that for the four (4) categories of environmental issues, Malaysians have the highest awareness towards water pollution and reflect the highest intention to conduct conservative action simultaneously. However, it is notable to mention that the result showed the opposite for climate change. Thus, the intervening factor that comes across is cost saving for water and energy. The environmental behaviour that reflected by Malaysians is caused by cost saving rather than their environmental awareness. Also, waste management and air quality protection failed to achieve the score as high as their environmental awareness level concurrently had suggested an intervening 
factor of convenience (Singhirunnusorn et al., 2012). The convenience implied in this context is referred to as practicing positive environmental behaviour out of convenience. For example, illegal dumping and open burning are easier than disposing of rubbish in a proper way, i.e., segregate and pack rubbish to dispose at waste disposal facilities. In the end this will lead to air pollution and poor waste management. To further elaborate, due to the inconvenience of public transport, Malaysians more willing to have personal drive, which contributes to excessive emissions from vehicles and poor air quality.

It is hope that this study can inspire the authorities and stakeholders, both from the government and non-government organization to realize the importace of fostering environmental awareness and environmental behaviour among Malaysian. These concerns improve the policy making considerations by blending the environmental awareness and behaviour performance to Malaysian culture. In the future, more facets of environmental issues such as biodiversity, forestry and wildlife restoration, and soil conservation should be addressed so that environmental awareness and behaviour performance among Malaysians can be measured in a more holistic course.

\section{Acknowledgement}

The authors would like to acknowledge that this work is supported by the Fundamental Research Grant Scheme with Cost Center No. R.J130000.7827.4F711 provided by Ministry of Higher Education, Malaysia. Also, sincere appreciation goes to the Ministry of Natural Resources and Universiti Teknologi Malaysia for supporting this study.

\section{References}

Afroz, R., Hassan, M. N., \& Ibrahim, N. A. (2003). Review of Air Pollution and Health Impacts in Malaysia. Environmental Research, 92(2), 71-77

Altin, A., Tecer, S., Tecer, L., Altin, S., \& Kahraman, B. F. (2014). Environmental Awareness Level of Secondary School Students: A Case Study in Balıkesir (Türkiye). Procedia - Social and Behavioral Sciences, 141(0), 12081214.

Asmuni, S., Khalili, J. M., \& Zain, Z. M. (2012). Sustainable Consumption Practices of University Students in Selangor, Malaysia. Journal of Asian Behavioural Studies, 2(6), 73-82

Azmi, S. Z., Latif, M.T., Ismail, A.S., Juneng, L., Jemain, A.A. (2010). Trend and Status of Air Quality at Three Different Monitoring Stations in the Klang Valley, Malaysia. Air Qual Atmos Health

Borhan, H., Ahmed, E. M., \& Hitam, M. (2013). CO2, Quality of Life and Economic Growth in East Asian 8. Journal of Asian Behavioural Studies, 3(8), 14-24

Chung, D., Muda, A., Omar, C. M. C., \& Manaf, L. A. (2012). Residents' Perceptions of the Visual Quality of OnSite Wastes Storage Bins in Kuching. Procedia - Social and Behavioral Sciences, 49(0), 227-236. 
Dominick, D., Juahir, H., Latif, M. T., Zain, S. M., \& Aris, A. Z. (2012). Spatial Assessment of Air Quality Patterns in Malaysia Using Multivariate Analysis. Atmospheric Environment, 60(0), 172-181.

Harth, N. S., Leach, C. W., \& Kessler, T. (2013). Guilt, Anger, and Pride about In-group Environmental Behaviour: Different Emotions Predict Distinct Intentions. Journal of Environmental Psychology, 34(0), 18-26.

Hassan, A. a., Noordin, T. A., \& Sulaiman, S. (2010). The Status on the Level of Environmental Awareness in the Concept of Sustainable Development Amongst Secondary School Students. Procedia - Social and Behavioral Sciences, 2(2), 1276-1280.

Hungerford, H. R. \& Volk, T. L. (1990). Changing Learner Behavior Through Environmental Education. The Journal of Environmental Education. 21(3), 8-21.

Karatekin, K. (2014). Social Studies Pre-service Teachers' Awareness of Solid Waste and Recycling. Procedia Social and Behavioral Sciences, 116(0), 1797-1801.

Keles, R. (2012). The Quality of Life and the Environment. Procedia - Social and Behavioral Sciences, 35(0), 2332.

Klöckner, C. A. (2013). A Comprehensive Model of the Psychology of Environmental Behaviour-A Meta-Analysis. Global Environmental Change, 23(5), 1028-1038.

Krajhanzl, J. (2010). Environmental and Pro-environmental Behaviour. School and Health, 21, 251-274.

Latif, S. A., Omar, M. S., Bidin, Y. H., \& Awang, Z. (2013). Analyzing the Effect of Situational Factor on Recycling Behaviour in Determining the Quality of Life. Journal of Asian Behavioural Studies, 3(8).

Latif, S. A., \& Omar, M. S. (2012). Recycling Behaviour in Tioman Island: A Case Study. Procedia-Social and Behavioral Sciences, 36, 707-715.

Marans, R. W. (2012). Quality of Urban Life Studies: An Overview and Implications for Environment-Behaviour Research. Procedia - Social and Behavioral Sciences, 35(0), 9-22.

McKenzie-Mohr, D. (2000). Promoting Sustainable Behavior: An Introduction to Community-based Social Marketing. Journal of Social Issues 56 (3), 543-554.

Moreno, T., Lavín, J., Querol, X., Alastuey, A., Viana, M., \& Gibbons, W. (2009). Controls on Hourly Variations in Urban Background Air Pollutant Concentrations. Atmospheric Environment, 43(27), 4178-4186.

Othman, F., M. E, A. E., \& Mohamed, I. (2012). Trend Analysis of A Tropical Urban River Water Quality in Malaysia. Journal of Environmental Monitoring, 14(12), 3164-3173.

Owens, S., \& Driffill, L. (2008). How to Change Attitudes and Behaviours in the Context of Energy. Energy Policy, 36(12), 4412-4418.

Seyedabrishami, S., Mamdoohi, A., Barzegar, A., \& Hasanpour, S. (2012). Impact of Carpooling on Fuel Saving in Urban Transportation: Case Study of Tehran. Procedia - Social and Behavioral Sciences, 54(0), 323-331.

Singhirunnusorn, W., Donlakorn, K., Kaewhanin, W., Kpxguvkicvgu, U., Kpচwgpekpi, H., Tge, J., \& Dgjcxkqwt, E. (2012). Household Recycling Behaviours and Attitudes toward Waste Bank Project: Mahasarakham Municipality. Journal of ASIAN Behavioural Studies, 2(6). 
Singhirunnusorn, W., Luesopa, P., Pansee, J., \& Sahachaisaeree, N. (2012). Students Behavior towards Energy Conservation and Modes of Transportation: A Case Study in Mahasarakham University. Procedia - Social and Behavioral Sciences, 35(0), 764-771. 